\title{
Clinical and Epidemiologic Characteristics of Hospitalized Patients with 2009 H1N1 Influenza Infection
}

\author{
Saygin Nayman Alpat, Gaye Usluer, Ilhan Ozgunes, Elif Doyuk Kartal, and Nurettin Erben \\ Department of Clinical Microbiology and Infectious Diseases, Faculty of Medicine, Eskisehir Osmangazi University, \\ 26480 Eskisehir, Turkey \\ Correspondence should be addressed to Saygin Nayman Alpat, snalpat@mynet.com
}

Received 2 November 2011; Revised 8 February 2012; Accepted 11 February 2012

Academic Editor: Zichria Zakay-Rones

Copyright (๑) 2012 Saygin Nayman Alpat et al. This is an open access article distributed under the Creative Commons Attribution License, which permits unrestricted use, distribution, and reproduction in any medium, provided the original work is properly cited.

\begin{abstract}
Objective. $2009 \mathrm{H} 1 \mathrm{~N} 1$ virus is a new virus that was firstly detected in April 2009. This virus spreads from human to human and causes a worldwide disease. This paper aimed to review the clinical and epidemiological properties of patients with $2009 \mathrm{H} 1 \mathrm{~N} 1$ influenza who were hospitalized and monitored at Eskisehir Osmangazi University Faculty of Medicine Hospital. Setting. A 1000bed teaching hospital in Eskisehir, Turkey. Patients-Methods. Between 05 November 2009-01 February 2010, 106 patients with 2009 H1N1 influenza, who were hospitalized, were prospectively evaluated. Results. Out of 106 patients who were hospitalized and monitored, 99 (93.4\%) had fever, $86(81.1 \%)$ had cough, 48 (45.3\%) had shortness of breath, $47(44.3 \%)$ had sore throat, $38(35.8 \%)$ had body pain, $30(28.3 \%)$ had rhinorrhea, $17(16 \%)$ had vomiting, $15(14.2 \%)$ had headache, and $14(13.2 \%)$ had diarrhea. When the patients were examined in terms of risk factors for severe disease, $83(78.3 \%)$ patients had at least one risk factor. During clinical monitoring, pneumonia was the most frequent complication with a rate of $66 \%$. While $47.2 \%$ of the patients were monitored in intensive care unit, $34 \%$ of them required mechanical ventilation support. Conclusion. Patients with $2009 \mathrm{H} 1 \mathrm{~N} 1$ influenza, who were hospitalized and monitored, should be carefully monitored and treated.
\end{abstract}

\section{Introduction}

$2009 \mathrm{H} 1 \mathrm{~N} 1$ virus is a new virus that was firstly detected in April 2009. This virus spreads from human to human and causes a worldwide disease.

In $2009 \mathrm{H} 1 \mathrm{~N} 1$ influenza, the symptoms include fever, tremor, rhinorrhea, cough, chest pain, body pain, headache, tiredness, diarrhea, and vomiting [1]. For 2009 H1N1 influenza infection, chronic lung disease, immunosuppression, and pregnancy were detected as risk factors for severe disease [2-4]. Throughout the pandemic period, a majority of the patients, who were below 2 years, above 65 years, and had underlying disease, were hospitalized and monitored $[5,6]$.

This study aimed to review the clinical and epidemiological properties of patients with $2009 \mathrm{H} 1 \mathrm{~N} 1$ influenza who were hospitalized and monitored at Eskisehir Osmangazi University, Faculty of Medicine Hospital.

\section{Materials and Methods}

Between 05 November 2009-01 February 2010, 106 patients with 2009 H1N1 influenza, who were hospitalized and monitored at Eskisehir Osmangazi University, School of Medicine Hospital, were prospectively evaluated. The patients' demographics, complaints related to admission to hospital, duration of disease, physical examination findings, laboratory and radiological findings, name of the clinic where monitoring was performed, underlying diseases (age, chronic pulmonary, cardiovascular, renal, hepatic, hematologic, metabolic disease, neuromuscular disease, taking immunosuppressive therapy, pregnancy, obesity), complications developed, and prognosis were recorded in the patient recruitment forms prepared.

Respiratory distress, tachypnea, chest pain, confusion, persistent vomiting, worsening of general condition, and 
TABle 1: Demographics of patients with 2009 H1N1 influenza.

\begin{tabular}{lcc}
\hline & Number of patients & $\%$ \\
\hline Gender & & \\
Male & 45 & 42.5 \\
Female & 61 & 57.5 \\
\hline Total & 106 & 100 \\
\hline Age group (years) & & \\
below 1 year & 7 & 6.6 \\
$1-4$ & 9 & 8.5 \\
$5-14$ & 10 & 9.4 \\
$15-24$ & 14 & 13.2 \\
$25-44$ & 40 & 37.7 \\
$45-64$ & 16 & 15.1 \\
above 65 years & 10 & 9.4 \\
Mean (SD) & $31.7(21.3)$ & \\
\hline Total & 106 & 100 \\
\hline
\end{tabular}

fever lasting more than three days were considered as a sign of serious illness, and these patients were hospitalized.

Criteria for hospitalization in patients with, in addition, persistent hypoxemia, hemodynamic instability, sepsis and shock findings, if any of the planned admission to intensive care unit patients. In-patients, patients without evidence of improvement in spite of antiviral therapy and supportive, progressive pulmonary infiltrate, persistent hypoxemia $(\mathrm{SpO} 2<92 \%)$, progressive hypercapnia, hemodynamic deterioration, signs of sepsis and shock in the case planned to be taken to intensive care unit patients.

Two thousand and nine H1N1 virus definitions by the World Health Organization, a national laboratory (Refik Saydam Hygiene Center) sent with the primary probe and positive controls, "Swine Influenza PCR Testing Kit," using "realtime reverse transcriptase polymerase chain reaction" was performed by analysis.

Statistical analysis, chisquare test, and Mann-Whitney $U$ test were used.

\section{Results}

Between 05 November 2009-01 February 2010, a total of 106 patients were hospitalized and monitored. The demographics of the patients are given in Table 1 . None of the patients had a history of vaccination against 2009 H1N1 virus.

Considering the provinces where the patients came from; $78(73.6 \%)$ of the patients were from Eskisehir, 17 (16\%) from Bilecik, 5 from (4.7\%) Kutahya, 2 (1.9\%) from Afyon, and $1(0.9 \%)$ each from Balikesir, Bursa, Istanbul, and Usak.

When the complaints of the patients who presented to the hospital were evaluated, out of 106 patients who were hospitalized and monitored, 99 (93.4\%) had fever, 86 (81.1\%) had cough, $48(45.3 \%)$ had shortness of breath, $47(44.3 \%)$ had sore throat, $38(35.8 \%)$ had body pain, $30(28.3 \%)$ had rhinorrhea, 17 (16\%) had vomiting, 15 (14.2\%) had headache, and $14(13.2 \%)$ had diarrhea (Figure 1).

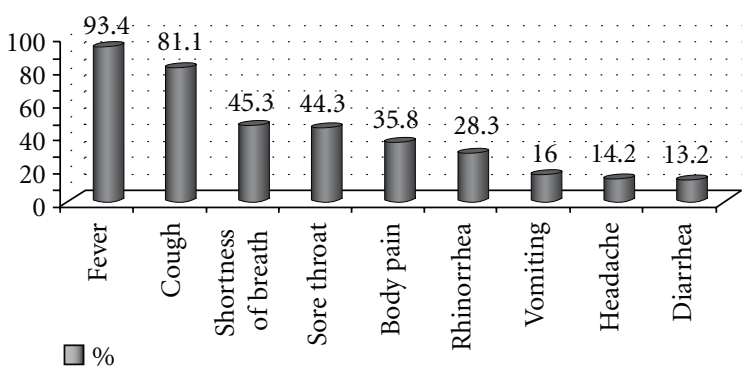

FIGURE 1: Complaints of the patients who presented to the hospital.

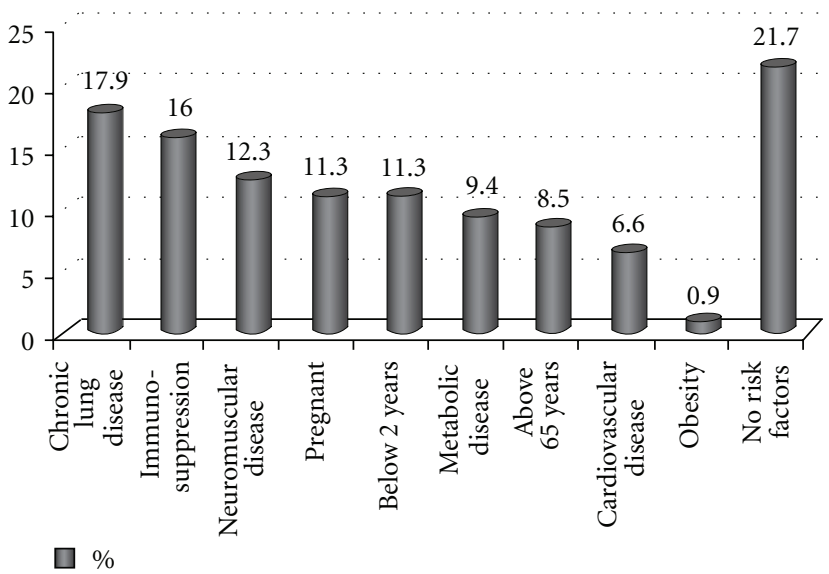

FIGURE 2: Risk factors for severe disease in patients.

When all patients were examined in terms of risk factors for severe disease, $83(78.3 \%)$ patients had at least one risk factor. $19(17.9 \%)$ of the patients had chronic lung disease, 17 (16\%) had immunosuppression, 13 (12.3\%) had neuromuscular disease, $12(11.3 \%)$ were pregnant, $12(11.3 \%)$ were below 2 years, 10 had $(9.4 \%)$ metabolic disease, 9 (8.5\%) were above 65 years, $7(6.6 \%)$ had cardiovascular disease, 1 $(0.9 \%)$ had obesity (Figure 2). 3 (25\%) of 12 monitored pregnant women developed complication of pneumonia. None of them required mechanical ventilation and no mortality was observed.

In patients, duration of disease ranged between 3-34 days $(10.9 \pm 5.6$ days on average) (Figure 3$)$. In 106 patients, who were hospitalized and monitored due to H1N1, virus identification was performed at National Influenza Laboratory with the analysis of real-time reverse transcriptase polymerase chain reaction. The complications, which occurred during clinical monitoring of the patients, are given in Table 2. In 16 of 70 cases of pneumonia, bacterial pneumonia was considered. Of these patients, blood and sputum cultures were negative. In Patients with suspected bacterial pneumonia, empiric treatment, were started according to guidelines.

In 106 patients with $2009 \mathrm{H} 1 \mathrm{~N} 1$ influenza who were hospitalized, $55(51.9 \%)$ were monitored in clinics of infectious diseases and $1(0.9 \%)$ in oncology. A total of $50(47.2 \%)$ patients consisting of $27(25.5 \%)$ patients were monitored in pediatrics, $19(17.9 \%)$ in thoracic diseases, $3(2.8 \%)$ 


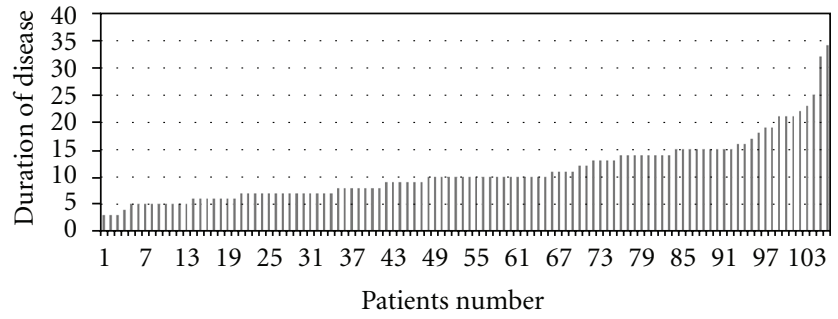

FIgURE 3: Duration of disease in patients.

TABLE 2: Complications seen in patients with $2009 \mathrm{H} 1 \mathrm{~N} 1$ influenza.

\begin{tabular}{lcc}
\hline Complication & Number of patients & $\%$ \\
\hline Pneumonia & 70 & 66 \\
Seizure & 2 & 1.89 \\
Hemoptysis & 1 & 0.94 \\
Pleural effusion & 1 & 0.94 \\
Pneumothorax & 1 & 0.94 \\
Pericarditis & 1 & 0.94 \\
Neutropenia & 1 & 0.94 \\
\hline Total & 77 & 72.6 \\
\hline
\end{tabular}

TABLE 3: Distribution of patients, who received ventilator support, by the clinics where they were monitored.

\begin{tabular}{lcc}
\hline & $\begin{array}{c}\text { Number of } \\
\text { patients }\end{array}$ & $\%$ \\
\hline Mechanical ventilator & 5 & 71.4 \\
$\quad$ Thoracic diseases intensive care & 1 & 14.3 \\
$\quad$ Pediatrics intensive care & 1 & 14.3 \\
$\quad$ Internal diseases intensive care & 7 & 100 \\
\hline Total & 3 & \\
\hline Noninvasive mechanical ventilator & 3 & 50 \\
$\quad$ Thoracic diseases intensive care & 6 & 100 \\
$\quad$ Pediatrics intensive care & & \\
\hline Total & 3 & 75 \\
\hline Noninvasive mechanical ventilator + & 1 & 25 \\
mechanical ventilator & 4 & 100 \\
$\quad$ Thoracic diseases intensive care & 3 \\
$\quad$ General surgery intensive care & & \\
\hline Total & 3 & \\
\hline
\end{tabular}

in internal diseases, and $1(0.9 \%)$ in general surgery intensive care units. During intensive care monitoring, 17 (34\%) patients required ventilation support associated with respiratory failure. $7(41.2 \%)$ of them were monitored with mechanical ventilator, $6(35.3 \%)$ were with noninvasive mechanical ventilator, and $4(23.5 \%)$ were with noninvasive mechanical ventilator and then with mechanical ventilator. Distribution of these patients per intensive care units is given in Table 3.

Oseltamivir treatment was administered to all patients for 5 days. 8 of 106 patients (7.5\%) with 2009 H1N1 influenza died. All deceased patients were those confirmed in terms
TABLE 4: Distribution per age for the deaths in patients.

\begin{tabular}{lcc}
\hline Age group (years) & Number of patients & $\begin{array}{c}\text { Number of deaths } \\
(\%)\end{array}$ \\
\hline below 1 year & 7 & $1(14.3)$ \\
$1-4$ & 9 & $0(0)$ \\
$5-14$ & 10 & $0(0)$ \\
$15-24$ & 14 & $2(14.3)$ \\
$25-44$ & 40 & $4(10)$ \\
$45-64$ & 16 & $0(0)$ \\
above 65 years & 10 & $1(10)$ \\
\hline
\end{tabular}

TABLE 5: Underlying diseases in deceased patients.

\begin{tabular}{lc}
\hline Underlying disease & $\begin{array}{c}\text { Number of deceased } \\
\text { patients }\end{array}$ \\
\hline Immunosuppression & 2 \\
Neuromuscular disease & 1 \\
Metabolic disease & 1 \\
Cardiovascular disease & 1 \\
Obesity & 1 \\
above 65 years + metabolic disease & 1 \\
below 2 years + neuromuscular disease & 1 \\
\hline Total & 8 \\
\hline
\end{tabular}

of $2009 \mathrm{H} 1 \mathrm{~N} 1$ virus by the laboratory. 5 of 7 patients (71.4\%), who were monitored with mechanical ventilator, and 2 of 4 patients (50\%), who were monitored with noninvasive mechanical ventilator and then with mechanical ventilator, died; on the other hand, all patients, who were monitored with only non-invasive mechanical ventilator, recovered. To be an underlying risk factor, there was no statistically significant relationship between the need of mechanical ventilation and death.

Distribution per age for the deaths in patients with 2009 H1N1 influenza is given in Table 4.

All deceased patients had underlying disease that posed risk (Table 5).

\section{Discussıon}

2009 H1N1 virus causes a disease at levels varying from mild to severe. While no treatment is required for some patients, hospitalization is required for some of them [1].

Considering the conducted studies, $95 \%$ of the patients with $2009 \mathrm{H} 1 \mathrm{~N} 1$ influenza consist of patients below 50 years $[2,7]$. In our patients with $2009 \mathrm{H} 1 \mathrm{~N} 1$ influenza, who were hospitalized and monitored, mean age was detected to be 31.7 similar to the mean ages stated in different studies [8$10]$.

In hospitalized patients, the symptoms, which were detected to be typical, were as follows: fever (95\%), cough $(88 \%)$, shortness of breath $(60 \%)$, tiredness $(43 \%)$, rhinorrhea $(38 \%)$, chest pain (31\%), headache (34\%), and myalgia $(36 \%)$. Gastrointestinal complaints such as vomiting and diarrhea are seen at a lower rate [11]. Top three complaints 
of the patients who presented to the hospital included fever at a rate of $93.4 \%$, cough at $81.1 \%$, and shortness of breath at $45.3 \%$. These complaints were followed, respectively, by sore throat, body pain, rhinorrhea, vomiting, headache, and diarrhea.

The following are considered to be risk factors for severe complications for $2009 \mathrm{H} 1 \mathrm{~N} 1$ influenza infection: age above 65, age below 2, pregnancy, and chronic diseases [1]. In different studies, in patients with $2009 \mathrm{H} 1 \mathrm{~N} 1$ influenza, underlying disease was reported to be at a rate of $68-73 \%$ $[10,11]$. When our patients were examined for underlying diseases which are possible risk factors, $78.3 \%$ of the patients had at least one risk factor. Chronic lung disease was detected in $17.9 \%$ of our patients, immunosuppression in $16 \%$, neuromuscular disease in $12.3 \%$, pregnancy in $11.3 \%$, metabolic disease in $9.4 \%$, cardiovascular disease in $6.6 \%$, and obesity in $0.9 \%$. While $11.3 \%$ of the patients consisted of those below 2 years, $8.5 \%$ of them comprised patients above 65 years. Pregnant women are under high risk in terms of morbidity and mortality associated with 2009 H1N1 influenza infection. In the studies conducted, abortus, birth defect, and preterm labor cases are reported [11-18]. 12 pregnant women were hospitalized and monitored in our hospital throughout pandemic period. No complication was seen except for pneumonia that developed in 3 patients. All patients recovered and discharged; no problem was experienced during their pregnancy followup.

The complications frequently reported for 2009 H1N1 influenza infection were pneumonia, bacterial coinfection, and exacerbation of underlying disease [19]. In our patients during clinical monitoring, pneumonia was the most frequent complication with a rate of $66 \%$.

In the study conducted by Louie et al. [10], 31\% of the patients with $2009 \mathrm{H} 1 \mathrm{~N} 1$ influenza, who were hospitalized and monitored, are reported to require stay in intensive care, and $65 \%$ of them required mechanical ventilation. Whereas in the study conducted by Riquelme et al. [19], rate of stay in intensive care is reported to be $22 \%$, and rate of patients who require mechanical ventilation is reported to be $68 \%$. While $47.2 \%$ of our patients were monitored in intensive care unit, $34 \%$ of them required mechanical ventilation support. Contrary to the patients reported in studies of the literature, in our hospitalized patients with $2009 \mathrm{H} 1 \mathrm{~N} 1$ influenza, it is observed that while indication of stay in intensive care is higher, requirement for mechanical ventilator is lower.

In our patients with $2009 \mathrm{H} 1 \mathrm{~N} 1$ influenza, mortality rate is at similar rates with other studies in the literature $[10,11]$. In a study conducted by Jain et al., underlying disease is reported at a rate of $68 \%$ in patients who present a mortal course [11]. In our case series, all patients, who presented a mortal course, had underlying disease.

\section{Conclusion}

For $2009 \mathrm{H} 1 \mathrm{~N} 1$ influenza infection, frequent presence of respiratory failure and requirement of mechanical ventilation in patients who needed hospitalization and developed pneumonia is notable. Unlike seasonal influenza, severe course, which is present also outside the risk groups, is noteworthy. Therefore, patients with $2009 \mathrm{H} 1 \mathrm{~N} 1$ influenza, who were hospitalized and monitored, should be carefully monitored and treated.

\section{Conflict of Interests}

All authors report no conflict of interests relevant to this paper.

\section{References}

[1] Centers for Disease Control and Prevention, "2009 H1N1 Flu ("Swine Flu") and You Centers for Disease Control and Prevention" http://www.cdc.gov/h1n1flu/qa.htm.

[2] F. S. Dawood, S. Jain, L. Finelli et al., "Emergence of a novel swine-origin influenza A (H1N1) virus in humans," The New England Journal of Medicine, vol. 360, no. 25, pp. 2605-2615, 2009.

[3] Centers for Disease Control and Prevention, "Hospitalized patients with novel influenza a (H1N1) virus infection-California," Morbidity and Mortality Weekly Report, vol. 58, no. 19, pp. 536-541, 2009.

[4] A. E. Fiore, D. K. Shay, K. Broder et al., "Prevention and control of seasonal influenza with vaccines: recommendations of the Advisory Committee on Immunization Practices (ACIP), 2009," Morbidity and Mortality Weekly Report, vol. 58, no. 8, pp. 1-52, 2009.

[5] A. E. Fiore, D. K. Shay, K. Broder et al., "Prevention and control of influenza: recommendations of the Advisory Committee on Immunization Practices (ACIP), 2008," Morbidity and Mortality Weekly Report, vol. 57, no. 7, pp. 1-60, 2008.

[6] W. W. Thompson, D. K. Shay, E. Weintraub et al., "Influenzaassociated hospitalizations in the United States," JAMA, vol. 292, no. 11, pp. 1333-1340, 2004.

[7] Centers for Disease Control and Prevention, "2009 pandemic influenza a (H1N1) virus infections-Chicago, illinois," Morbidity and Mortality Weekly Report, vol. 58, no. 33, pp. 913918, 2009.

[8] A. Nougairède, L. Ninove, C. Zandotti et al., "Novel virus influenza A (H1N1sw) in South-Eastern France, April-August 2009," PLoS One, vol. 5, no. 2, Article ID e9214, 2010.

[9] F. Tulloch, R. Correa, G. Guerrero et al., "Profile of the first cases hospitalized due to influenza A (H1N1) 2009 in Panama City, Panama, May-June 2009," Journal of Infection in Developing Countries, vol. 3, no. 11, pp. 811-816, 2009.

[10] J. K. Louie, M. Acosta, K. Winter et al., "Factors associated with death or hospitalization due to pandemic 2009 influenza A(H1N1) infection in California," JAMA, vol. 302, no. 17, pp. 1896-1902, 2009.

[11] S. Jain, L. Kamimoto, A. M. Bramley et al., "Hospitalized patients with $2009 \mathrm{H} 1 \mathrm{~N} 1$ influenza in the United States, AprilJune 2009," The New England Journal of Medicine, vol. 361, no. 20, pp. 1935-1944, 2009.

[12] D. J. Jamieson, M. A. Honein, S. A. Rasmussen et al., "H1N1 2009 influenza virus infection during pregnancy in the USA," The Lancet, vol. 374, no. 9688, pp. 451-458, 2009.

[13] L. Dodds, S. A. McNeil, D. B. Fell et al., "Impact of influenza exposure on rates of hospital admissions and physician visits because of respiratory illness among pregnant women," CMAJ, vol. 176, no. 4, pp. 463-468, 2007. 
[14] K. M. Neuzil, G. W. Reed, E. F. Mitchel, L. Simonsen, and M. R. Griffin, "Impact of influenza on acute cardiopulmonary hospitalizations in pregnant women," American Journal of Epidemiology, vol. 148, no. 11, pp. 1094-1102, 1998.

[15] D. W. Freeman and A. Barno, "Deaths from Asian influenza associated with pregnancy," American Journal of Obstetrics and Gynecology, vol. 78, pp. 1172-1175, 1959.

[16] L. Lindsay, L. A. Jackson, D. A. Savitz et al., "Community influenza activity and risk of acute influenza-like illness episodes among healthy unvaccinated pregnant and postpartum women," American Journal of Epidemiology, vol. 163, no. 9, pp. 838-848, 2006.

[17] S. A. Rasmussen, D. J. Jamieson, K. MacFarlane, J. D. Cragan, J. Williams, and Z. Henderson, "Pandemic influenza and pregnant women: summary of a meeting of experts," American Journal of Public Health, vol. 99, no. 2, pp. S248-S254, 2009.

[18] Centers for Disease Control and Prevention, "Hospitalized patients with novel influenza A (H1N1) virus infection-California," Morbidity and Mortality Weekly Report, vol. 58, pp. 536-541, 2009.

[19] R. Riquelme, M. Riquelme, M. L. Rioseco et al., "Characteristics of hospitalised patients with $2009 \mathrm{H} 1 \mathrm{~N} 1$ influenza in Chile," European Respiratory Journal, vol. 36, no. 4, pp. 864 $869,2010$. 


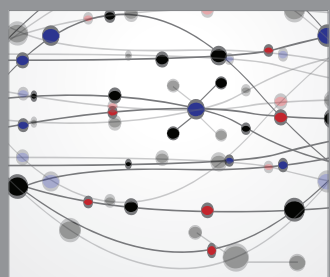

The Scientific World Journal
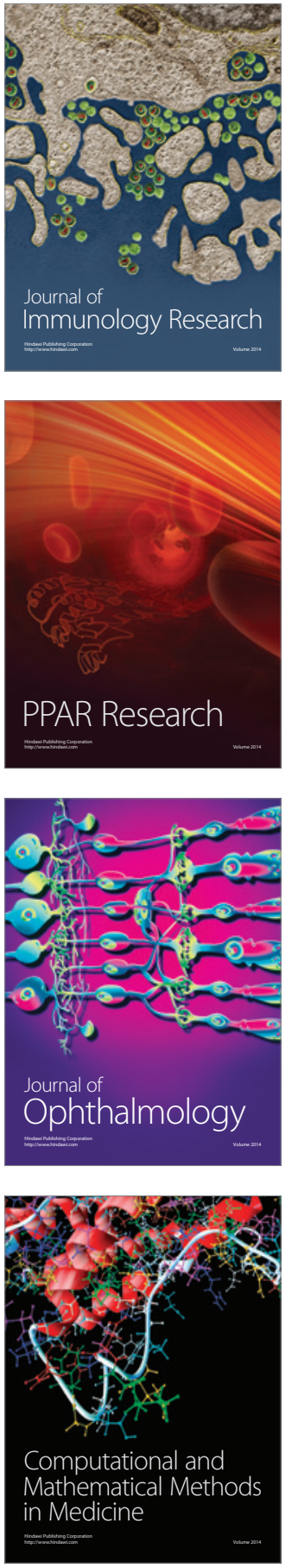

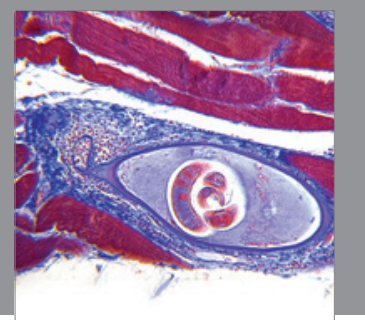

Gastroenterology

Research and Practice
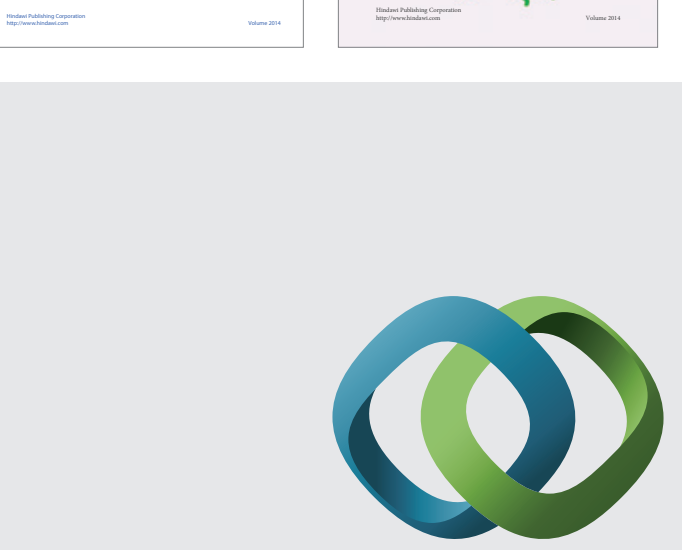

\section{Hindawi}

Submit your manuscripts at

http://www.hindawi.com
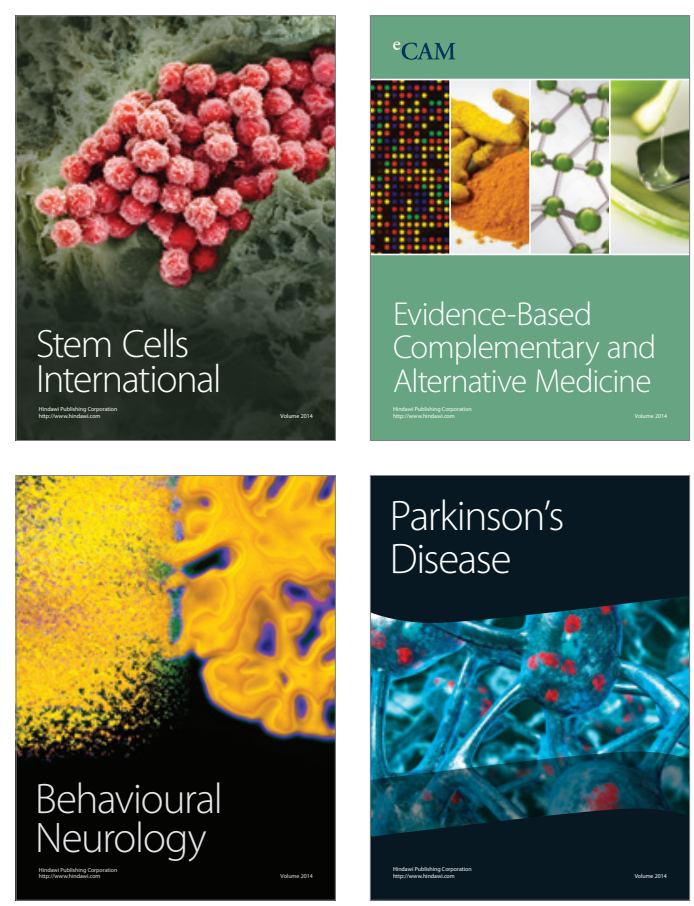

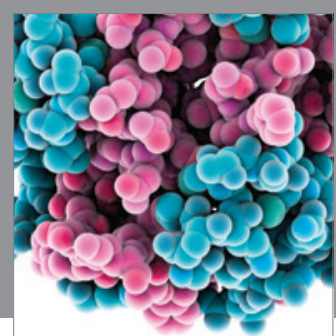

Journal of
Diabetes Research

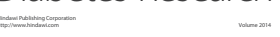

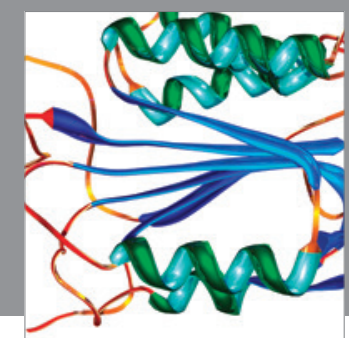

Disease Markers
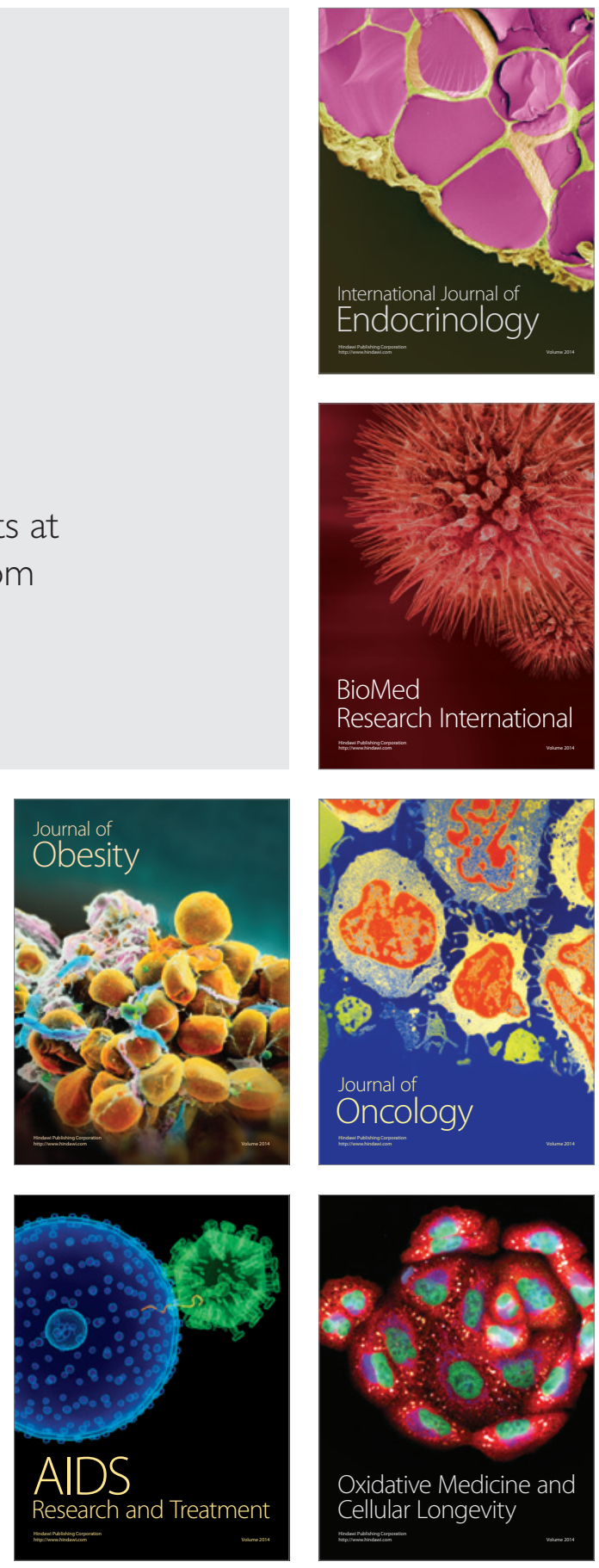